\title{
Thiol methyltransferase activity in colonocytes and erythrocyte membranes
}

\author{
W J Babidge, S H Millard, W E W Roediger
}

\begin{abstract}
Aims-To verify the improved thiol methyltransferase (TMT) assay and measure activity in isolated colonocytes and erythrocyte membranes of the same subjects.

Methods-High performance liquid chromatography with radioactivity detection was used to measure ${ }^{14} \mathrm{C}$-methylmercaptoethanol formation, the reaction product of cell extracts incubated with mercaptoethanol and ${ }^{14} \mathrm{C}-\mathrm{S}$-adenosylmethionine. Results-Verification of radiolabelled ${ }^{14} \mathrm{C}$ methylmercaptoethanol was by exogenous addition of methylmercaptoethanol and simultaneous ultraviolet detection at $214 \mathrm{~nm}$. Using a substrate concentration of $10 \mathrm{mM}$ mercaptoethanol, the $\mathrm{Km}$ for $\mathrm{S}$ adenosylmethionine was $25 \mu \mathrm{M}$. The sensitivity of the radioactive method was 2 pmol, with coefficients of variation of $7 \%$ within assay and $6.4 \%$ between assay. TMT activities (mean $\pm \mathbf{S E}$; $\mathbf{n}=17$ ) were $471 \pm 64 \mathrm{pmol} / \mathrm{hour} / \mathrm{mg}$ protein for colonocytes and $73 \pm 7 \mathrm{pmol} / \mathrm{hour} / \mathrm{mg}$ protein for erythrocyte membranes.

Conclusions-The direct assay of TMT activity is sensitive, specific and eliminates concern over non-enzymatic methylation of thiol compounds. High activities in colonic epithelial cells deserve evaluation in disease states.

(f Clin Pathol 1995;48:641-644)
\end{abstract}

Keywords: Thiol methyltransferase, colonocytes, methylation.

Thiol methyltransferase (TMT; EC 2.1.1.9) activity of tissues promotes methylation of harmful sulphydryl compounds to less harmful methylated products. ${ }^{12}$ Activity of TMT is reduced in Parkinson's disease ${ }^{3}$ and rheumatoid arthritis. ${ }^{4}$ Both low ${ }^{1}$ and high activities ${ }^{5}$ have been reported in the colonic mucosa. As ulcerative colitis may be caused by excess production of sulphides in the colonic lumen, ${ }^{6}$ there seemed to be an advantage in accurately measuring TMT activity of colonic epithelial cells where the enzyme would be essential for detoxification of sulphides.

Measurement of TMT activity, as established by Weinshilboum et $a l^{7}$ involves conversion of 2-mercaptoethanol to S-methylmercaptoethanol using the radiolabelled methyl donor ${ }^{14} \mathrm{C}$-S-adenosylmethionine, extraction into toluene and scintillation counting. To account for non-enzymatic formation of unlabelled S-methylmercaptoethenol, activities of other methyltransferases and radioactive con- taminants in the methyl donor, three different types of blank corrections were used. A method utilising high performance liquid chromatography (HPLC) with ultraviolet detection ${ }^{3}$ and later modified by concentration of tissue extracts has been reported (Waring R, 1993, personal communication). The present work reports a direct method for detection of the enzyme product by HPLC using an online radioactivity monitor requiring no concentration steps or multiple blank corrections. Measurements were made on isolated colonocytes and erythrocyte membranes.

\section{Methods}

Tissue and blood samples were obtained from 17 patients (seven men, 10 women) undergoing colectomy for benign or malignant disease. Colonocytes were prepared from pathologically uninvolved segments of colon as described previously $^{8}$ except that dithiothreitol was omitted. After isolation, colonocytes were washed twice in $0.1 \mathrm{M}$ dipotassium hydrogen orthophosphate/1 mM EDTA (pH 7.4), then ground finely in liquid nitrogen using a mortar and pestle. Erythrocyte membranes were isolated as described by Pazmino and Weinshilboum ${ }^{9}$ except that $20 \mathrm{ml}$ of heparinised blood was used and storage was in $0.1 \mathrm{M}$ dipotassium hydrogen orthophosphate/1 mM EDTA (pH $7 \cdot 4$ ) following grinding in liquid nitrogen. Colonocytes and erythrocyte membranes were divided into two aliquots: one was assayed immediately and the other stored at $-70^{\circ} \mathrm{C}$.

TMT assays were performed on the supernatant fraction of colonocyte suspensions or entire suspensions of erythrocyte membranes. Prior to assay, protein concentrations of samples were determined. ${ }^{10} \mathrm{~A}$ heated blank sample was prepared by incubating the sample at $70^{\circ} \mathrm{C}$ for 30 minutes, then placing on ice until assay. TMT activity was determined by a modification of the method of Weinshilboum et $\mathrm{al}^{7}$ based on the conversion of 2-mercaptoethanol to labelled S-methylmercaptoethanol using the methyl donor S-adenosyl$1-\left[\right.$ methyl $\left.-{ }^{14} \mathrm{C}\right]$ methionine (specific activity $10.6 \mu \mathrm{Ci} / \mu \mathrm{mol}$; Amersham International, Amersham, UK). The final mercaptoethanol concentration in the reaction $\mathrm{mix}$ was $10 \mathrm{mM}$ and that of S-adenosylmethionine was $54 \mu \mathrm{M}$. Incubation was at $37^{\circ} \mathrm{C}$ for 50 minutes and the reaction stopped by adding an equal volume of acetonitrile, which was used to make samples compatible with the mobile phase of the HPLC. Reaction tubes were kept on ice for 30 minutes before centrifugation for five minutes at $16000 \times g$ at $4^{\circ} \mathrm{C}$. A portion of the supernatant 


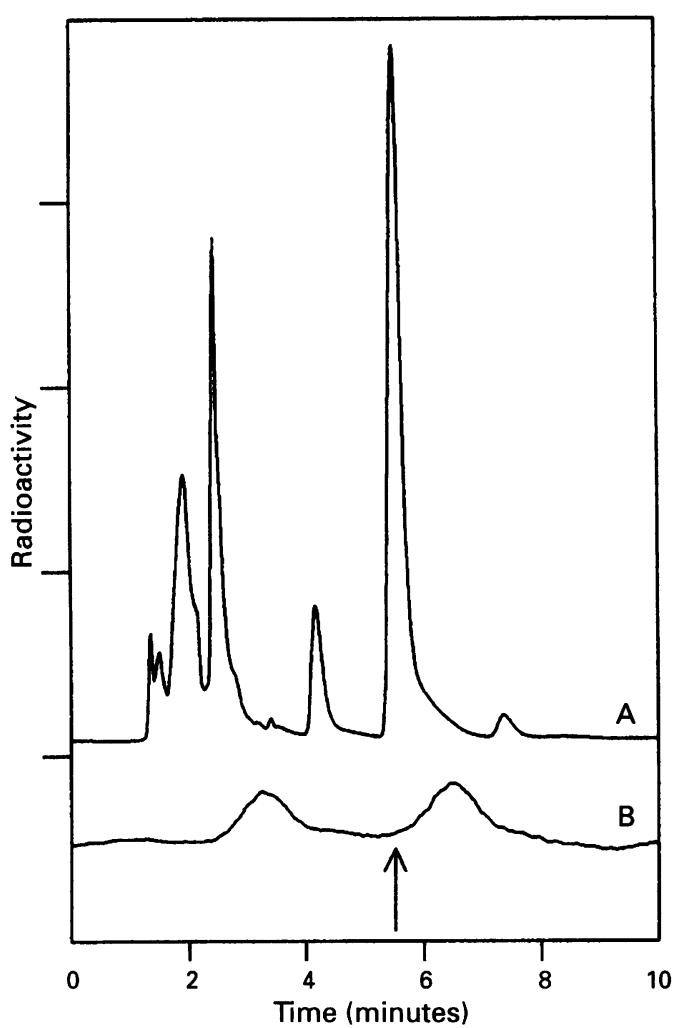

Figure 1 HPLC chromatograms of exogenously added methylmercaptoethanol (1 $\mathrm{mM}$ ) in homogenates of isolated human colonocytes measured by ultraviolet detection at $214 \mathrm{~nm}(A)$ and radioactivity detection (B). Arrow indicates start of the methylmercaptoethanol peak.

fluid $(20 \mu \mathrm{l})$ was injected onto the HPLC. Methylmercaptoethanol (final concentration $1 \mathrm{mM}$ ) was added to extracts of five patient

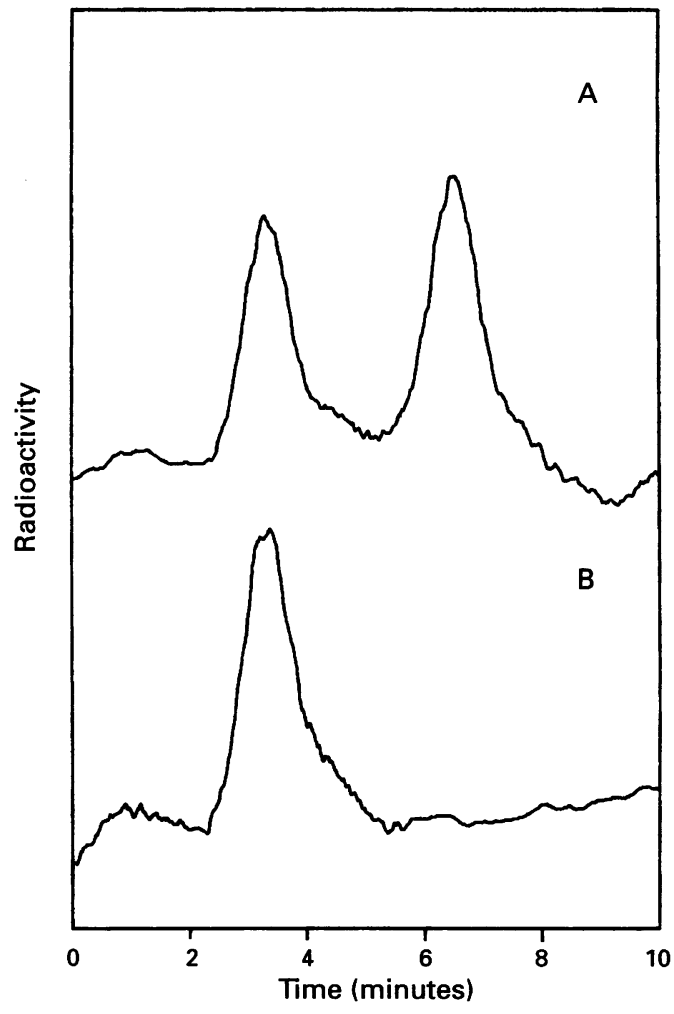

Figure 2 HPLC chromatograms (radioactivity detection) of ${ }^{14} \mathrm{C}$-methylmercaptoethanol (6.5 minutes) - $(A)$ homogenate of isolated coloncytes (TMT activity 114 pmol/hour/mg protein) and (B) heated blank sample. The peak at 2.5 minutes is unknown.

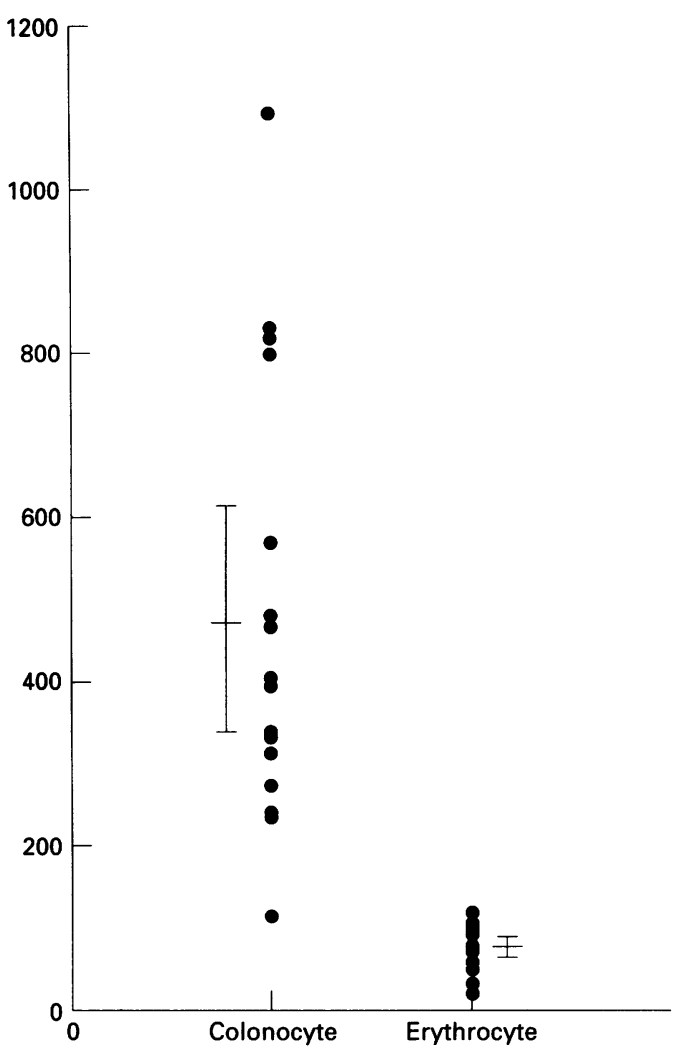

Figure 3 TMT activity (pmol/hour/mg protein) in colonocytes and erythrocyte membranes (mean $\pm S E$ of 17 cases).

samples and simultaneously detected at $214 \mathrm{~nm}$ to verify the retention time of the radiolabelled methylmercaptoethanol.

A Waters HPLC system (Millipore Australia Pty Ltd, Sydney, Australia) was used for quantitation of ${ }^{14} \mathrm{C}$-methylmercaptoethanol. This consisted of 510 HPLC pump, 715 Ultra Wisp sample processor and Baseline 810 chromatography software. Detection was with a Berthold HPLC radioactivity monitor, \#LB507A (Bartlett Instruments Pty Ltd, Melbourne, Australia) with an admixture cell (Z1000-4) and T-mixer. The liquid scintillation cocktail used was Flo-Scint V from Packard (Canberra-Packard Pty Ltd, Melbourne, Australia). The analytical column was an Alltech Spherisorb ODS-2, 5 micron (\#8738), $250 \times 4.6 \mathrm{~mm}$ (Alltech Australia, Sydney, Australia). Mobile phase consisted of $20 \%$ methanol : $80 \%$ distilled water at a flow rate of $1 \mathrm{ml} /$ minute. The ratio of Flo-Scint $\mathrm{V}$ to mobile phase was $4: 1$.

\section{CALCULATIONS}

The Michaelis-Menten ( $\mathrm{Km})$ constant was calculated from a Lineweaver-Burk transformation using five concentrations of S-adenosylmethionine between 9 and $144 \mu \mathrm{M}$.

TMT activity was calculated as pmol of methylmercaptoethanol formed. The peak area $(\mu \mathrm{V}$-sec) was converted to disintegrations per minute $(\mathrm{dpm})$ after determining a conversion factor by injecting a known amount of ${ }^{14} \mathrm{C}-\mathrm{S}$ adenosylmethionine and relating area to dpm. The specific activity of S-adenosylmethionine 
was then used to calculate pmol of methylmercaptoethanol formed and results expressed as $\mathrm{pmol} / \mathrm{hour} / \mathrm{mg}$ protein.

\section{Results}

The retention time of ${ }^{14} \mathrm{C}$-methylmercaptoethanol was about 6.5 minutes. The retention times of ultraviolet and radioactivity detection differed slightly as the $1 \mathrm{ml}$ flow cell of the radioactivity monitor results in a broader peak; however, both peaks started at $5 \cdot 4$ minutes (fig 1). Linearity of TMT activity was found in samples diluted with $0 \cdot 1 \mathrm{M}$ dipotassium hydrogen orthophosphate/1 mM EDTA ( $\mathrm{pH} 7 \cdot 4)$ to a protein concentration between 0.1 and $0.3 \mathrm{mg} / 20 \mu \mathrm{l}$. Mercaptoethanol was used at $10 \mathrm{mM}$, this being the upper expected concentration of sulphides in the colon. Using this concentration of mercaptoethanol, the $\mathrm{Km}$ for S-adenosylmethionine was $25 \mu \mathrm{M}$, determined using three different colonocyte suspensions. The final concentration of S-adenosylmethionine in the reaction mix was $54 \mu \mathrm{M}$. The effect of incubation time was tested using 15 minute increments up to two hours. A linear correlation between product formation and time of incubation was found up to one hour. An incubation time of 50 minutes was chosen for all experiments. No methylmercaptoethanol was identifiable by ultraviolet detection in unconcentrated cell homogenates. Using the methylmercaptoethanol standard solution, the minimum detectable level by ultraviolet detection was $100 \mathrm{nmol}$ compared with the radioactivity method, which was 2 pmol (determined as twice noise level). The coefficient of variation of five replicate measurements was $7 \%$ within assay and $6.4 \%$ between assay. No methylated product was detectable when the sample was pretreated by heating at $70^{\circ} \mathrm{C}$ for 30 minutes (fig 2). Similarly, blanks without substrate showed no methylmercaptoethanol product (data not shown).

Results of TMT activity (pmol/hour/mg protein) in 17 patients are shown in fig 3 . There was a fivefold variation for erythrocyte membranes and a 10-fold variation for colonocyte suspensions. TMT activity was found to be stable in homogenates of erythrocyte membranes and colonocytes kept at $-70^{\circ} \mathrm{C}$ for up to eight months.

\section{Discussion}

HPLC was chosen for measurement of TMT activity, as the reaction product methylmercaptoethanol can be detected with specificity and ease. The HPLC method of Waring et $a l^{3}$ measured reduction in total mercaptoethanol concentrations rather than the formation of its methylated product. Subsequent modification of their method has involved concentration of the toluene extract which enabled detection of methylmercaptoethanol by ultraviolet detection (Waring $\mathrm{R}, 1993$, personal communication). We were unable to detect methylmercaptoethanol by ultraviolet de- tection in tissue extracts not subjected to tissue concentration, a problem circumvented by radioactivity detection, which is at least four orders of magnitude more sensitive than ultraviolet detection. Heat inactivation and concurrent ultraviolet HPLC incorporating radioactivity detection provided evidence that the present method is specific for measurement of the methylmercaptoethanol product of the enzymatic reaction.

A variety of thiol compounds such as mercaptoethanol, hydrogen sulphide and methanethiol have been used to measure TMT activity with S-adenosylmethionine as the methyl donor. ${ }^{11}$ Mercaptoethanol was chosen as the substrate for the present assay as hydrogen sulphide and methanethiol are volatile at physiological $\mathrm{pH}$ values. ${ }^{1}$

The fivefold variation in erythrocyte membrane TMT activity in our patient group is similar to that reported previously. ${ }^{7}$ At a substrate concentration of $10 \mathrm{mM}$, chosen for the current study, both low and high affinity TMT activities are measured, both of which in erythrocytes have similar biochemical properties and are regulated in a parallel fashion. ${ }^{12}$ Similarly, biphasic substrate kinetics were found by Glauser $e a^{13}$ in hepatic microsomes.

Present results of TMT activity in colonocytes are difficult to compare with those of others due to the use of different substrates and substrate concentrations. Weisiger et al ${ }^{1}$ using 2-thioacetanalide reported colonic mucosal activity of $125 \mathrm{fmol} / \mathrm{mg} /$ minute. Pacifici et $a l^{14}$ found $0.38 \mathrm{nmol} / \mathrm{minute} / \mathrm{mg}$ protein using 2-mercaptoethanol. In a further study ${ }^{5}$ TMT activity in microsomal fractions of the entire colonic mucosa comprising epithelial, immune and muscle cells was 786, 1791 and $964 \mathrm{pmol} / \mathrm{minute} / \mathrm{mg}$ protein in ascending, transverse and descending colon, respectively. The average TMT activity of isolated colonocytes in the current study was $471 \mathrm{pmol} / \mathrm{hour} /$ $\mathrm{mg}$ protein $(7.9 \mathrm{pmol} / \mathrm{minute} / \mathrm{mg}$ protein). The lower activities presently reported compared with Pacifici et $a l^{5}$ would be expected as whole cell homogenates rather than microsomal subfractions were used. The variation in enzyme activity in our study was 10 -fold in colonocytes, compared with a variation of 1.5 -fold in the transverse colon and sixfold in the ascending colon found by Pacifici et al. ${ }^{5}$

The method presented in this paper is both specific and sensitive for the measurement of the methylated product of the reaction of mercaptoethanol with S-adenosylmethionine catalysed by TMT. It is applicable for measurement of TMT activity in erythrocyte membranes and will be useful for future assessment of thiol methylation in isolated colonocytes from patients with ulcerative colitis reported to be exposed to high thiol concentration ${ }^{15}$ from the gut lumen.

1 Weisiger RA, Pinkus LM, Jakoby WB. Thiol s-methyltransferase: suggested role in detoxification of intestinal hydrogen sulphide. Biochem Pharmacol 1980;29:2885-7.

2 Keith RA, Jardine I, Kerremans A, Weinshilboum RM Human erythrocyte membrane thiol methyltransferase. S-methylation of captopril, n-acetylcysteine and 7-thiospirolactone. Drug Metab Dispos 1984;12:717-24.

3 Waring RH, Sturman SG, Smith MCG, Steventon GB 
Heafield MTE, Williams AC. S-methylation in motor neuron disease and Parkinson's disease. Lancet 1989;ii 356-7.

4 Bradley H, Waring RH, Emery P. Reduced thiol methyl transferase activity in red blood cell membranes from patients with rheumatoid arthritis. $\mathcal{f}$ Rhematol 1991;18: patients

5 Pacifici GM, Romiti P, Santerini S, Giuliani L. S-methyltransferases in human intestine: differential distribution transferases in human intestine: differential distribution
of the microsomal thiol methyltransferase and cytosolic of the microsomal thiol methyltransferase and cytosolic
thiopurine methyltransferase along the human bowel. thiopurine methyltransferase

6 Roediger WEW, Duncan A, Kapaniris O, Millard S. Reducing sulphur compounds of the colon impair colonocyte nutrition: implications for ulcerative colitis. Gastroenterology 1993;104:802-9.

7 Weinshilboum RM, Sladek S, Klumpp S. Human erythrocyte thiol methyltransferase: radiochemical microassay 71 .

8 Roediger WEW, Truelove SC. Method of preparing isolated colonic epithelial cells (colonocytes) for metabolic studies. Gut 1979;20:484-8.
9 Pazmino PA, Weinshilboum RM. Human erythrocyte phenol o-methyltransferase: radiochemical microassay and biochemical properties. Clin Chim Acta 1978;89:317-29. 10 Lowry OH, Rosebrough NJ, Faar AL, Randall RJ. Protein 193:265-75.

11 Bremer J, Greenberg DM. Enzymatic methylation of foreign sulfhydryl compounds. Biochim Biophys Acta 1961;46: sulfhydryl

12 Keith RA, Abraham RT, Pazmino P, Weinshilboum RM. Correlation of low and high affinity thiol methyltransferase
and phenol methyltransferase activities in humam erythand phenol methyltransferase activities in humam eryth-

13 Glauser TA, Kerremans AC, Weinshilboum RM. Human hepatic microsomal thiol methyltransferase. Assay conditions, biochemical properties, and correlation studies. Drug Metab Dispos 1992;20:247-55.

14 Pacifici GM, Santerini S, Giuliani L, Rane A. Thiol methyltransferase in humans: development and tissue distribution. Dev Pharmacol Ther 1991;17:8-15.

15 Macfarlane GT, Gibson GR, Cummings JH. Comparison of fermentation reactions in different regions of the human of fermentation reactions in different regl Bacteriol 1992;72:57-64. 